Terbit online pada laman : http://teknosi.fti.unand.ac.id/

\title{
Pemanfaatan Metode Naïve Bayes dalam Implementasi Sistem Pakar Untuk Menganalisis Gangguan Perkembangan Anak
}

\author{
Meza Silvana ${ }^{a,}{ }^{*}$ Ricky Akbar ${ }^{b}$, Alfi Syahnum ${ }^{c}$ \\ a,b,c Jurusan Sistem Informasi, Fakultas Teknologi Informasi, Universitas Andalas, Limau Manis, Padang 25163, Indonesia
}

\section{INFORMASI ARTIKEL}

Sejarah Artikel:

Diterima Redaksi: 16 Maret 2019

Revisi Akhir: 14 Juli 2020

Diterbitkan Online: 30 Agustus 2020

\section{KATA KUNCI}

Gangguan perkembangan anak,

Naive bayes,

Posterior

KORESPONDENSI

E-mail: meza@it.unand.ac.id

\section{PENDAHULUAN}

Perkembangan dan pertumbuhan anak sangat dipengaruhi oleh banyak pihak seperti peran orang tua, keluarga dan lingkungan. Kualitas perkembangan tersebut biasanya dinilai melalui proses tumbuh kembang sang anak tiap tahunnya. Tiap orang tua tentunya menginginkan anak yang sehat yang ditandai dengan pertumbuhan yang baik[3][10][13]. Berdasarkan hasil survei dari sumber Balitbang 2006 terhadap 696 anak SD pada empat provinsi di Indonesia didapatkan sekitar 33\% dari anak yang disurvey tersebut mengalami gangguan perilaku dan emosi[8]. Gangguan Perkembangan Anak (GPA)/Children Development Disorder merupakan masalah mental anak yang sering diabaikan oleh orang tua. Masalah ini akan menjadi serius ketika pelakunya sudah mengganggu orang lain dan lingkungannya. Untuk itu diperlukan pemahaman dan pengetahuan masyarakat yang cukup dalam mengenali gangguan perkembangan anak secara dini. Dengan demikian gangguan tumbuh kembang anak dini dapat diketahui lebih cepat, sehingga upaya pencegahan, stimulasi, penyembuhan serta pemulihan dapat diberikan dengan indikasi yang jelas pada masa-masa kritis proses tumbuh kembang[8].

Ada banyak pemahaman yang berbeda terkait dengan pendeteksian GPA secara dini. Selama ini GPA ini seringkali dianggap sepele atau sebaliknya masyarakat cederung untuk menutup-nutupi penyimpangan ini karena stigma/cap buruk yang telah melekat di dalam masyarakat. Ketakutan akan stigma ini menyebabkan penanganan gangguan ini seringkali menjadi terlambat. Selain itu tiap orang memiliki sudut pandang dan pemahaman yang tidak sama. Oleh karena itu, diperlukan sebuah aplikasi yang mudah digunakan oleh masyarakat secara umum untuk membantu dalam deteksi dini ini secara objektif. Salah 
satunya adalah aplikasi kesehatan dengan memanfaatkan pengolahan data mining[1][2][9].

Penerapan data mining dalam menemukan pola dari tumpukan data saat ini sudah merambah segala sektor kehidupan[11][12][14], termasuk sektor kesehatan. Pola fikir masyarakat yang selama ini masih menganggap bahwa tenaga kesehatan adalah satu-satunya hal yang dipercaya dalam mendiagnosa penyakit, mulai bergeser dengan diterapkannya berbagai metode artificial intelligence/machine learning dalam data mining pada aplikasi komputer yang dikenal sebagai sistem Pakar. Salah satu sistem pakar tersebut adalah naïve bayes. Metode ini memungkinkan sistem mampu mendeteksi penyakit melalui gejala yang diinputkan pada aplikasi tersebut[4][5]. Penerapan naïve bayes dalam melatih kepakaran dari sistem pada penelitian ini diharapkan dapat membantu menjawab permasalahan masyarakat tersebut[13][14].

\section{METODE}

\subsection{Proses Penelitian}

Penelitian ini didapatkan melalui studi literatur dan eksperimen/observasi dengan menggunakan beberapa tahapan diantaranya: studi literatur, pengumpulan data, pemilihan atribut/parameter, perancangan model aplikasi, Penerapan aplikasi/implementasi, evaluasi hasil, dan dokumentasi Eksperimen.

Alur penerapan naive bayes dalam penelitian ini digambarkan pada diagram alir naive bayes yang dapat dilihat pada gambar 1 .

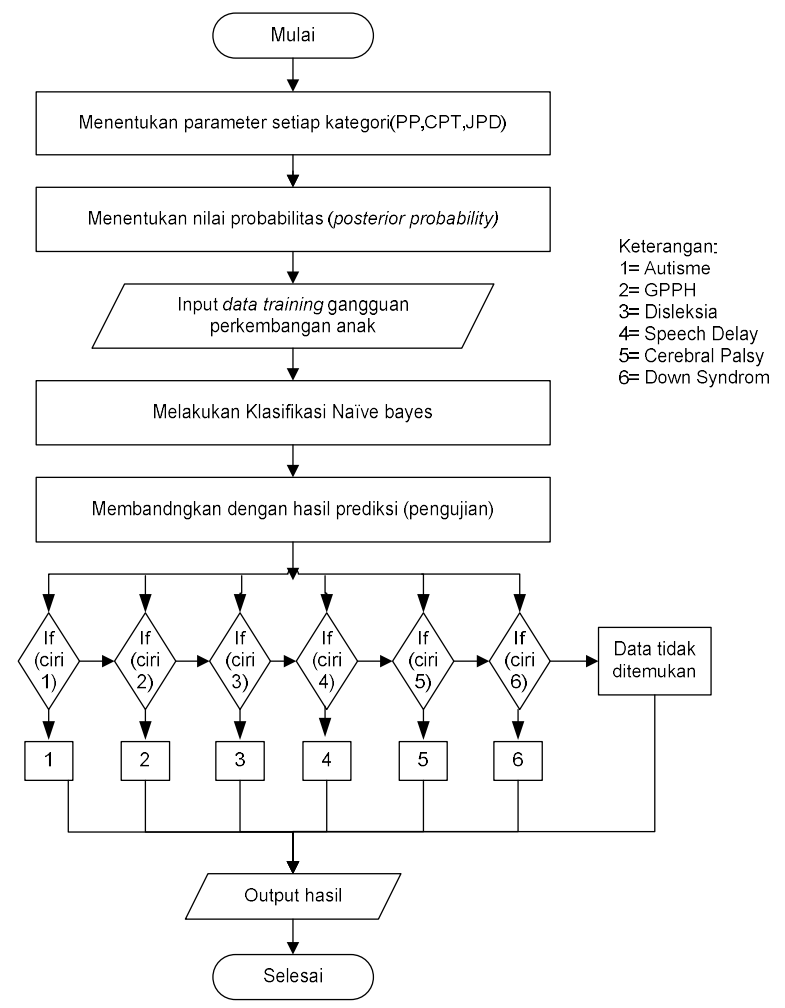

Gambar 1. Rancangan Klasifikasi Gangguan Perkembangan Anak Menggunakan Naive bayes
Perhitungan nilai probabilitas pada penelitian ini menggunakan persamaan 1:

$$
P(H \mid E)=\frac{P(E \mid H) \quad P(H)}{P(E)}
$$

Dari persamaan 1, diketahui bahwa $\mathrm{P}(\mathrm{H} \backslash \mathrm{E})$ adalah probabilitas akhir bersyarat suatu hipotesis, $\mathrm{H}$, akan terjadi jika diberikan bukti (evidence), E, terjadi. sedangkan $\mathrm{P}(\mathrm{E} \backslash \mathrm{H})$ adalah probabilitas munculnya evidence, E, yang akan mempengaruhi nilai hipotesis H. $\mathrm{P}(\mathrm{H})$ merupakan probabilitas awal (prior) hipotesis $\mathrm{H}$ tanpa memandang evidence apapun, kemudian $\mathrm{P}(\mathrm{E})$ merupakan probabilitas awal (prior) evidence E yang terjadi. Secara sederhana dapat dikatakan bahwa probabilitas dari hipotesa kita terhadap suatu kejadian sama dengan probabilitas kejadian yang memberikan hipotesis dikalikan dengan probabilitias hipotesa yang kemudian dinormalkan[14].

\subsection{Diagram Alir Naive bayes}

Perancangan sistem dapat dijelaskan sebagai berikut[4][9][12]:

\subsubsection{Membangun struktur Naive bayes}

Bentuk struktur Naive bayes adalah mengelompokkan setiap gejala sesuai jenisnya berdasarkan informasi dari data yang didapatkan.

\subsubsection{Perancangan Inference Engine (Model Referensi Sistem)}

Inference Engine/mesin inferensi memberikan/menguji aturan satu demi satu sampai kondisi aturan itu benar dan memberikan hipotesa yang benar.

\subsubsection{Menentukan Parameter /Prior probability}

Dalam menentukan parameter dari setiap gejala dengan cara memberi nilai kepercayaan dari setiap gejala. Untuk setiap gejala yang direpresentasikan mempunyai estimasi parameter yang didapat dari data yang telah ada atau pengetahuan dari seorang pakar. Setiap pakar bisa mempunyai nilai kepercayaan yang berbeda. Jika lebih dari satu pakar, maka data yang diambil adalah nilai rata-rata pakar tersebut.

\subsubsection{Membuat Conditional Probability Table}

Conditional probability (probabilitas bersyarat) adalah probabilitas suatu event B terjadi apabila event A sudah terjadi. Dalam hal ini, B adalah munculnya gangguan perkembangan pada anak, sedangkan A adalah gejala yang sudah muncul. Sebuah tabel yang berisi probabilitas dari setiap kemungkinan nilai dari A dan B disebut dengan Conditional Probability Table (CPT).

\subsubsection{Membuat Tabel Joint Probability distribution}

Setelah mendapatkan nilai Prior Probability, dan CPT gangguan perkembangan anak, kemudian ditentukan nilai Joint Probability Distribution (JPD). Nilai JPD didapatkan dengan cara mengalikan nilai CPT dengan Prior Probability.

\subsubsection{Menghitung Posterior Probability}

Untuk mendapatkan nilai posterior probability, dapat dihitung dari hasil JPD yang telah diperoleh, kemudian nilai inilah yang 
digunakan untuk menghitung probabilitas kemunculan suatu gejala. Nilai posterior probability dicari dengan persamaan 4[12]:

$$
\text { Posterior }=\frac{\text { present }(J P D)}{\text { present }(J P D)+\operatorname{absent}(J P D)}
$$

Untuk menghitung kinerja sistem dapat dihitung dengan persamaan (3) dan (4) sebagai berikut [4]:

$$
\begin{aligned}
& \text { Akurasi }=\frac{\text { Jumlah data yang diprediksi secara benar }}{\text { Jumlah prediksi yang dilakukan }} \\
& \text { Error }=\frac{\text { Jumlah data yang diprediksi secara salah }}{\text { Jumlah prediksi yang dilakukan }}
\end{aligned}
$$

\section{HASIL}

\subsection{Sumber Data}

Dari sumber data yang telah diperoleh, terdapat 25 sumber data terpilih yang dibagi menjadi dua kelompok sebagai data Prior dan data testing. Tabel penyebaran data primer dari sumber data

\begin{tabular}{|c|c|c|c|}
\hline Responden & $\begin{array}{c}\text { Total } \\
\text { Responden }\end{array}$ & $\begin{array}{l}\text { Data } \\
\text { Prior }\end{array}$ & $\begin{array}{c}\text { Data } \\
\text { Testing }\end{array}$ \\
\hline $\begin{array}{l}\text { Dokter Spesialis } \text { Anak } \\
\text { (SpA) }\end{array}$ & 2 & 2 & - \\
\hline Dokter Residen Anak & 8 & 3 & 5 \\
\hline Dokter Umum & 2 & 1 & 1 \\
\hline Perawat Anak & 4 & 2 & 2 \\
\hline $\begin{array}{l}\text { Mahasiswa Psikologi } \\
\text { Tingkat Akhir }\end{array}$ & 9 & 2 & 7 \\
\hline Jumlah & 25 & 10 & 15 \\
\hline
\end{tabular}
terpilih dapat dilihat pada tabel.1.

Tabel 1. Data Primer

Berdasarkan tabel 1, dari total data, untuk Prior data digunakan 10 sumber dan data testing adalah 15 sumber. Data Prior dijadikan sebagai pemodelan dalam klasifikasi gangguan perkembangan anak, sedangkan data testing digunakan untuk proses pengujian. Selanjutnya, dari data kuisioner gejala didapatkan 25 buah gejala gangguan perkembangan anak yang dapat dilihat pada tabel 2.

\subsection{Hasil Pengolahan Data Kuesioner}

Setelah mendapatkan data prior probability dari pakar (data kuisioner), gejala dapat dikelompokkan menggunakan perhitungan tingkat probabilitas yang mengikuti konsep certainty factor 0,3 berbanding 0,7 sehingga didapatkan tiga jenis gejala yaitu, gejala utama, gejala sedang dan gejala ringan.

Dimana:

$\mathrm{A}=$ Gejala Ringan (nilai kebenaran $=0,01-0,3)($ lebih mendekati nol persen)

$\mathrm{B}=$ Gejala Sedang (nilai kebenaran $=0,3-0,7)$

$\mathrm{C}=$ Gejala Utama (nilai kebenaran $=0,7-0,95))($ lebih mendekati seratus persen)

Setelah menentukan rentang nilai, kemudian menghitung nilai prior gejala gangguan perkembangan pada anak. Sebelumnya ditentukan dulu nilai kepercayaan terhadap responden. Dalam kasus ini, responden dibagi menjadi 2 bagian yaitu pakar dan non pakar. $70 \%$ dari $100 \%$ total kepercayaan adalah nilai untuk pakar gangguan perkembangan pada anak dan $30 \%$ nilai untuk non pakar. Angka diatas berdasarkan dari 10 kuesioner, yang terbagi atas 5 pakar gangguan perkembangan pada anak dan 5 non pakar. Pakar yang dimaksud disini adalah dokter spesialis anak dan dokter residen anak, dan non pakar yang dimaksudkan adalah dokter umum, perawat anak, dan mahasiswa psikologi tingkat akhir. Untuk huruf $\mathrm{C}$ pada kuesioner pakar adalah 0,14 didapatkan dari $70 \%$ dari rentang nilai maximal huruf $\mathrm{C}$ pada tabel 4.4. Rentang nilai maximal huruf $\mathrm{C}$ pada tabel 4.4 adalah 0,95 . Lalu dapat kita hitung $70 \%$ dari nilai 0.95 adalah 0,7 . Maka nilai 0,7 tersebut dibagi dengan jumlah responden pakar yaitu 5 . Maka diperoleh lah nilai 0,14 untuk huruf $\mathrm{C}$ pada pakar. Sedangkan untuk nilai 0,06 pada kuesioner non pakar adalah sisa dari nilai pakar yaitu $30 \%$ dari 0,95 adalah 0,3 . Nilai 0,3 tersebut dibagi dengan jumlah responden non pakar yaitu 5. Maka diperoleh lah nilai 0,06 untuk huruf $\mathrm{C}$ pada non pakar. Begitu seterusnya yang dilakukan untuk memperoleh nilai prior $\mathrm{B}$ dan $\mathrm{C}$ untuk masing-masing pakar dan non pakar.

\subsection{Perhitungan Nilai Parameter}

Untuk mendapatkan nilai parameter, sebelumnya dibutuhkan rentang nilai untuk pengisian kuesioner gunanya data kuesioner lebih mudah untuk diolah dan menentukan nilai gejala dari responden. Rentang nilai untuk mengelompokkan jenis gejala pada metode Bayesian Network secara umum dapat dilihat pada tabel.2 [3].

Tabel 2. Rentang Nilai Gejala Gangguan Perkembangan Anak

\begin{tabular}{llc}
\hline Jenis Gejala & Rentang Nilai & $\begin{array}{c}\text { Isian pada } \\
\text { Kuesioner }\end{array}$ \\
\hline Gejala Primer/ Utama & $0,7-0,95$ & $\mathrm{C}$ \\
\hline Gejala Sekunder/ Sedang & $0,3-0,7$ & $\mathrm{~B}$ \\
\hline Gejala ringan & $0,01-0,3$ & $\mathrm{~A}$ \\
\hline
\end{tabular}

Gejala primer atau utama adalah gejala yang sangat mempengaruhi gangguan perkembangan pada anak. Gejala sekunder adalah gejala yang mempengaruhi gangguan perkembangan pada anak, namun tidak terlalu signifikan. Gejala ringan adalah gejala yang pengaruhnya sangat kecil terhadap gangguan perkembangan pada anak. Dari kuesioner data primer yang telah didapatkan, dihasilkan turunan gejala dari pakar yang dapat dilihat pada tabel 3 .

\subsection{Pembentukan Inference Engine}

Inference Engine berisi dengan rule-based knowledge atau pembentukan aturan gejala gangguan perkembangan pada anak dengan memakai inferensi forward chaining. Contoh langkah inference engine adalah seperti yang pada langkah berikut ini:

1. If Konsentrasi mudah teralihkan(x1) Then Hiperaktif.

2. If Tidak sabar(x3) And Gerak-gerik kurang tertuju(x12) And Konsentrasi mudah teralihkan(x1) And Suka gelisah(x4) Then Hiperaktif.

3. If Konsentrasi mudah teralihkan(x1) And Tidak sabar(x3) And Suka gelisah(x4) Then Hiperaktif. 
4. If Konsentrasi mudah teralihkan(x1) And Suka gelisah(x4) Then Hiperaktif.

5. If Gerak-gerik kurang tertuju(x12) And Konsentrasi mudah teralihkan(x1) Then Hiperaktif.

6. If Konsentrasi mudah teralihkan(x1) And Tidak sabar(x3) Then Hiperaktif.

7. If Sulit membaca dan mengeja(x5) Then Disleksia.

8. If Sulit dalam berhitung(x10) And Sulit mengingat nama atau sebuah objek(x8) And Percaya diri rendah(x9) And Sulit membaca dan mengeja(x5) Then Disleksia.

9. If Sulit membaca dan mengeja(x5) And Pasif dalam berkomunikasi(x6) And Terlambat bicara(x13) Then Disleksia.

10. If Sulit membaca dan mengeja(x5) And Terlambat bicara(x13) Then Disleksia.

11. Dan seterusnya

Tabel 3. Rentang Nilai Gejala Gangguan Perkembangan Anak

\begin{tabular}{cl}
\hline Kode Gejala & Jenis Gejala \\
\hline x1 & Konsentrasi mudah teralihkan \\
x2 & Kata-kata yang diucapkan tidak jelas \\
x3 & Tidak sabar \\
x4 & Suka gelisah \\
x5 & Sulit membaca dan mengeja \\
x6 & Pasif dalam berkomunikasi \\
x7 & Masih tetap kesulitan dalam berpakaian \\
x8 & Sulit mengingat nama atau sebuah objek \\
x9 & Percaya diri rendah \\
x10 & Sulit dalam berhitung \\
x11 & Ekspresi muka kurang hidup \\
x12 & Gerak-gerik kurang tertuju \\
x13 & Terlambat bicara \\
x14 & Tidak dapat mengendalikan urinasi selama \\
& aktivitas fisik \\
x15 & Kelemahan dalam mengendalikan otot \\
x16 & Seringgorokan, mulut dan lidah \\
x17 & selalu mengeluarkan air liur \\
x18 & Sulit mengontrol gerakan menulis \\
x19 & Terpaku pada suatu kegiatan yang ritualistik \\
& atau rutinitas yang tak ada gunanya \\
x20 & Mempunyai paras muka yang hampir sama \\
x21 & seperti muka orang Mongol \\
x22 & Mengguan mengunyah dan menelan \\
x23 & Tidak kelemahat dan mognembedakan bahaya atau tidak \\
x24 & Marah bila rutinitas yang seharusnya berubah \\
x25 & Memperhatikan tangannya sendiri \\
\hline &
\end{tabular}

\subsection{Implementasi Sistem}

Pada tahap implementasi sistem telah dibuat halaman aplikasi sistem gangguan perkembangan pada anak . Gambar 2 berikut menampilkan hasil user sudah memilih beberapa gejala gangguan serta gangguan yang terdeteksi seperti pada gambar 2 .

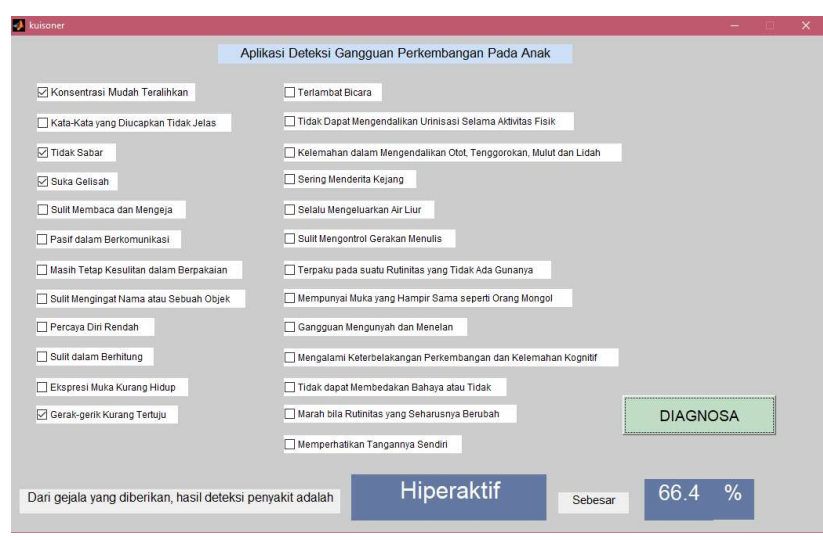

Gambar 2. Tampilan Halaman Sistem Diagnosis Gangguan Perkembangan

Pada tahap implementasi ini dapat dilihat bahwa ada 25 buah input gejala dengan nilai parameter telah tersimpan di dalam sistem sesuai dengan langkah yang telah dijelaskan pada bagian 2.2.1-2.2.6 berupa tampilan halaman aplikasi sistem gangguan perkembangan pada anak. Tampilan ini bersifat user friendly seperti yang dapat dilihat pada gambar 2, sehingga memudahkan pengguna dalam mengimputkan gejala secara mandiri, kemudian dengan menekan tanda diagnosa maka sistem akan menampilkan hasil yang dapat dilihat langsung oleh pengguna di halaman yang sama. Tampilan pada gambar 2 ini adalah contoh pengguna menginputkan beberapa gejala dan hasil yang didapatkan adalah gejala tersebut merupakan ciri-ciri anak yang bersifat hiperaktif.

\subsection{Pengujian Sistem}

Pengujian sisten dujikan kepada 10 orang pakar dan 15 orang non pakar. Hasil pengujian sistem dapat dilihat pada tabel 4 dan 5 .

Tabel 4. Contoh perbandingan hasil pengujian sistem terhadap pakar

\begin{tabular}{clll}
\hline Uji Ke & Pakar & Sistem & Ket. \\
\hline Pakar 1 & & & \\
1 & Hiperaktif & Hiperaktif & Sesuai \\
2 & Disleksia & Disleksia & Sesuai \\
3 & Autisme & Hiperaktif & Tidak Sesuai \\
4 & Speech Delay & Speech Delay & Sesuai \\
5 & Celebral Palsy & - & Tidak Sesuai \\
6 & Down Syndrome & Down Syndrome & Sesuai \\
\hline Pakar 2 & & & \\
\hline 1 & Hiperaktif & Hiperaktif & Sesuai \\
2 & Disleksia & Disleksia & Sesuai \\
3 & Autisme & Autisme & Sesuai \\
4 & Speech Delay & Speech Delay & Sesuai \\
5 & Celebral Palsy & Celebral Plasy & Sesuai \\
6 & Down Syndrome & Down Syndrome & Sesuai \\
\hline Pakar 3 & & & \\
\hline 1 & Hiperaktif & Hiperaktif & Sesuai \\
2 & Disleksia & Disleksia & Sesuai \\
3 & Autisme & - & Tidak Sesuai
\end{tabular}




\begin{tabular}{clll}
4 & Speech Delay & Speech Delay & Sesuai \\
5 & Celebral Palsy & - & Tidak Sesuai \\
6 & Down Syndrome & Down Syndrome & Sesuai \\
\hline Pakar 4 & & & \\
\hline 1 & Hiperaktif & Hiperaktif & Sesuai \\
2 & Disleksia & Disleksia & Sesuai \\
3 & Autisme & - & Tidak Sesuai \\
4 & Speech Delay & Speech Delay & Sesuai \\
5 & Celebral Palsy & Celebral Plasy & Sesuai \\
$\mathbf{6}$ & Down Syndrome & Down Syndrome & Sesuai \\
\hline Pakar 5 & & & \\
\hline 1 & Hiperaktif & Hiperaktif & Sesuai \\
2 & Disleksia & Autisme & Tidak Sesuai \\
3 & Autisme & Autisme & Sesuai \\
4 & Speech Delay & Speech Delay & Sesuai \\
5 & Celebral Palsy & Celebral Plasy & Sesuai \\
6 & Down Syndrome & Down Syndrome & Sesuai \\
\hline
\end{tabular}

Tabel 5. Contoh perbandingan Hasil pengujian system terhadap non Pakar

\begin{tabular}{|c|c|c|c|}
\hline Uji Ke & Non Pakar & Sistem & Ket. \\
\hline \multicolumn{4}{|c|}{ Non Pakar 1} \\
\hline 1 & Hiperaktif & Hiperaktif & Sesuai \\
\hline 2 & Disleksia & Disleksia & Sesuai \\
\hline 3 & Autisme & Autisme & Sesuai \\
\hline 4 & Speech Delay & Speech Delay & Sesuai \\
\hline \multirow[t]{2}{*}{5} & Celebral Palsy & Celebral Palsy & Sesuai \\
\hline & Down & Down & \\
\hline 6 & Syndrome & Syndrome & Sesuai \\
\hline \multicolumn{4}{|c|}{ Non Pakar: } \\
\hline \multirow{3}{*}{1} & & & Tidak \\
\hline & Hiperaktif & - & Sesuai \\
\hline & & Down & Tidak \\
\hline 2 & Disleksia & Syndrome & Sesuai \\
\hline 3 & Autisme & Autisme & Sesuai \\
\hline 4 & Speech Delay & Speech Delay & Sesuai \\
\hline \multirow[t]{2}{*}{5} & Celebral Palsy & Celebral Palsy & Sesuai \\
\hline & Down & Down & \\
\hline 6 & Syndrome & Syndrome & Sesuai \\
\hline \multicolumn{4}{|c|}{ Non Pakar: } \\
\hline 1 & Hiperaktif & Hiperaktif & Sesuai \\
\hline \multirow[t]{2}{*}{2} & Disleksia & Disleksia & Sesuai \\
\hline & & & Tidak \\
\hline \multirow[t]{2}{*}{3} & Autisme & - & Sesuai \\
\hline & & & Tidak \\
\hline \multirow[t]{2}{*}{4} & Speech Delay & - & Sesuai \\
\hline & & & Tidak \\
\hline 5 & Celebral Palsy & Hiperaktif & Sesuai \\
\hline
\end{tabular}

\section{PEMBAHASAN}

\subsection{Pengujian Sistem}

Untuk mendapatkan nilai akurasi, sistem menggunakan persamaan (3) terhadap hasil prcobaan. Berdasarkan hasil pengujian didapatkan nilai kebenaran sistem untuk pengujian data pakar dengan tingkat keakuratan data Prior pakar untuk hasil uji adalah sebesar $83,33 \%$. Sedangkan nilai kebenaran sistem untuk pengujian data non pakar dengan tingkat keakuratan data Prior non pakar untuk hasil uji sebesar $73,33 \%$. Hal ini sesuai dengan teorinya bahwa pakar memiliki kompetensi dibandingkan non pakar dalam menilai gejala dari suatu gangguan penyakit.

\section{KESIMPULAN}

Berdasarkan hasil testing yang dilakukan terhadap pakar dan non pakar didapatkan bahwa sistem ini mengikuti logika berpikir secara umum. Hasil pengujian pakar lebih tinggi keakuratan datanya dibanding dengan keakuratan non pakar. Hal ini sesuai karena pada kenyataannya pakar memang menguasai bidang gangguan perkembangan anak sedangkan non pakar ada yang masih kurang menguasai secara lengkap tentang gangguan perkembangan anak tersebut. Dengan demikian sistem ini telah mampu menciptakan sebuah model yang mengikuti logika pakar untuk mendeteksi secara dini gangguan perkembangan pada anak.

\section{DAFTAR PUSTAKA}

[1] A. Desiani. \& M. Arhami., Konsep Kecerdasan Buatan, Edisi Pertama, Yogyakarta: Andi, 2006. 
[2] D.T. Larose, Discovering Knowledge in Data : An Introduction to Data Mining," Canada: John Wiley \& Sons. 2005.

[3] E. Turban, J.E. Aronson, T. P. Liang, Decision Support Systems and Intelegent Systems, Edisi Pertama, New Delhi: Prentice-Hall of India, 2005.

[4] P. N. Tan, M. Steinbach,V. Kumar, Introduction to Data Mining, Boston: Pearson Education, 2006.

[5] A.N. Chamidah, "Deteksi Dini Gangguan Pertumbuhan dan Perkembangan Anak", Jurnal pendidikan Khusus, Vol.5 No.2 hal. 83-93, 2009.

[6] T.R. Patil, S. S. Sherekar, "Performance Analysis of Naive Bayes and J48 Classification Algorithm for Data Classification," International Journal of Computer Science And Applications, Vol.6 No.2 pp 256-261, 2013.

[7] Lukman, A. \& Nur, M. N. A., "Algoritma Bayesian Network Untuk Simulasi Prediksi Pemenang PILKADA Menggunakan MSBNx," Jurnal informatika Multimedia, Vol.2 hal.100-107, 2013.

[8] Rahayu, S. M, "Deteksi dan Intervensi Dini pada Anak Autis". Jurnal Pendidikan Anak, 2014, Vol. 3 Ed.1 Hal. 420-428.

[9] Dahria, M., Silalahi, R. \& Ramadhan, M., "Sistem Pakar Metode Damster Shafer Untuk Menentukan Jenis Gangguan Perkembangan Pada Anak," Jurnal Ilmiah SAINTIKOM, Vol. 12 No. 1,2013.

[10] Menteri Kesehatan Republik Indonesia. Peraturan Menteri Kesehatan Republik Indonesia Nomor 66 tahun 2014 tentang Pemantauan Pertumbuhan, Perkembangan, Dan Gangguan Tumbuh Kembang Anak.

[11] Fitriaini. "Implementasi Sistem Pakar pada Handphone Andorid untuk Diagnosis Penyakit Paru dengan Metode Bayesian Network, " S1, Universitas Andalas, Padang, 2014.

[12] N. Abdullah, "Mengenal Anak Berkebutuhan Khusus," S1, Universitas Bengkulu, 2013.

[13] S. L. Ginting, R. P. Trinanda, “ Penggunaan Metode Naïve Bayes Classifier Pada Aplikasi Perpustakaan,"

[14] R. Kurniawan., "Sistem Pakar Untuk Mendiagnosa Penyakit Mata Dengan Metode Bayesian Network," S1, Universitas Islam Negeri Sultas Syarif Kasim, Pekan Baru: 2011.

[15] A. Kusumawati,'Penanganan Kognitif Anak Down Syndrome Melalui Metode Kartu Warna di TK Permata Bunda Surakarta Tahun Ajaran 2013/2014," S1, Surakarta, 2013.

[16] S.Yakub, "Sistem Pakar Deteksi Penyakit Diabetes Mellitus Dengan Menggunakan Pendekatan Naïve Bayesian Berbasis Web," S1, Universitas Islam Negeri Malang, Malang: 2008.

[17] Rodiyah, "Efektivitas Terapi Wicara Untuk Meningkatkan Kemampuan Berbahasa Anak Dengan Gangguan Cerebral Palsy Di Yayasan Pembinaan Anak Cacat (YPAC) Malang," S1, Universitas Islam Negeri Maulana Malik Ibrahim, Malang: 2012

\section{BIODATA PENULIS}

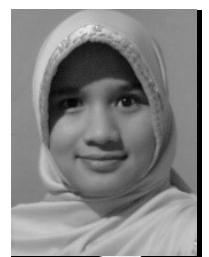

Meza Silvana

Menyelesaikan jenjang S1 di Jurusan Teknik Elektr di Universitas Andalas dengan bidang kajian speech processing, kemudian melanjutkan. S2 di jurusan yang sama dengan bidang kajian machine learning dan image processing. Fokus bidang penelitian saat ini adalah data science, machine learning, speech recognition dan image processing.

\section{Ricky Akbar}

Menyelesaikan jenjang S1 di Jurusan Sistem informasi di Universitas Putra Indonesia di bidang Intelligent System, kemudian melanjutkan. S2 juga di Jurusan Sistem Informasi di Universitas yang sama juga di bidang Intelligent System. Fokus bidang penelitian saat ini adalah adalah data visualisation, enterprise application dan machine learning..

\section{Alfi Syahnum}

Menyelesaikan jenjang S1 di Jurusan Sistem Informasi di Universitas Andalas dengan bidang kajian data mining.

\section{LAMPIRAN}

Tabel. 6: Rincian Hasil pengujian data testing pakar dan system

\begin{tabular}{|c|c|c|c|}
\hline Kode & Gejala & $\begin{array}{c}\text { Jenis } \\
\text { Gangguan }\end{array}$ & $\begin{array}{c}\text { Hasil } \\
\text { Sistem }\end{array}$ \\
\hline 1 & $\begin{array}{l}\text { Konsentrasi mudah } \\
\text { teralihkan }\end{array}$ & \multirow{3}{*}{ Hiperaktif } & \multirow{3}{*}{ Hiperaktif } \\
\hline 3 & Tidak Sabar & & \\
\hline 4 & Suka gelisah & & \\
\hline 5 & $\begin{array}{l}\text { Sulit membaca dan } \\
\text { mengeja }\end{array}$ & \multirow{2}{*}{ Disleksia } & \multirow{2}{*}{ Disleksia } \\
\hline 13 & Terlambat bicara & & \\
\hline 1 & $\begin{array}{l}\text { Konsentrasi mudah } \\
\text { teralihkan }\end{array}$ & & \\
\hline 2 & $\begin{array}{l}\text { Kata-kata yang } \\
\text { diucapkan tidak jelas }\end{array}$ & & \\
\hline 3 & Tidak sabar & & \\
\hline 4 & Suka gelisah & & \\
\hline 5 & $\begin{array}{l}\text { Sulit membaca dan } \\
\text { mengeja }\end{array}$ & & \\
\hline 6 & $\begin{array}{ll}\text { Pasif dalam } \\
\text { berkomunikasi }\end{array}$ & Autisme & Autisme \\
\hline 7 & $\begin{array}{l}\text { Masih tetap kesulitan } \\
\text { dalam berpakaian }\end{array}$ & & \\
\hline 8 & $\begin{array}{l}\text { Sulit mengingat nama } \\
\text { atau sebuah objek }\end{array}$ & & \\
\hline 9 & Percaya diri rendah & & \\
\hline 10 & Sulit dalam berhitung & & \\
\hline 12 & $\begin{array}{l}\text { Gerak-gerik kurang } \\
\text { tertuju }\end{array}$ & & \\
\hline
\end{tabular}




\begin{tabular}{|c|c|c|c|}
\hline 13 & Terlambat bicara & & \\
\hline 19 & $\begin{array}{l}\text { Terpaku pada suatu } \\
\text { kegiatan } \\
\text { ritualistik atau rutinitas } \\
\text { yang tak ada gunanya }\end{array}$ & & \\
\hline 22 & $\begin{array}{l}\text { mengalami } \\
\text { keterbelakangan } \\
\text { perkembangan dan } \\
\text { kelemahan kognitif }\end{array}$ & & \\
\hline 23 & $\begin{array}{lr}\text { Tidak } & \text { dapat } \\
\text { membedakan } & \text { bahaya } \\
\text { atau tidak } & \end{array}$ & & \\
\hline 24 & $\begin{array}{l}\text { Marah } \\
\text { yang } \\
\text { berubah }\end{array}$ & & \\
\hline 25 & $\begin{array}{l}\text { Memperhatikan } \\
\text { tangannya sendiri }\end{array}$ & & \\
\hline 2 & $\begin{array}{l}\text { Kata-kata yang } \\
\text { diucapkan tidak jelas }\end{array}$ & \multirow{4}{*}{$\begin{array}{l}\text { Speech } \\
\text { Delay }\end{array}$} & \multirow{4}{*}{$\begin{array}{l}\text { Speech } \\
\text { Delay }\end{array}$} \\
\hline 10 & Sulit dalam berhitung & & \\
\hline 13 & Terlambat bicara & & \\
\hline 18 & $\begin{array}{l}\text { Sulit mengontrol } \\
\text { gerakan menulis }\end{array}$ & & \\
\hline 7 & $\begin{array}{l}\text { Masih tetap kesulitan } \\
\text { dalam berpakaian }\end{array}$ & \multirow{4}{*}{$\begin{array}{l}\text { Celebral } \\
\text { Palsy }\end{array}$} & \multirow{4}{*}{$\begin{array}{l}\text { Celebral } \\
\text { Palsy }\end{array}$} \\
\hline 15 & $\begin{array}{lr}\text { Kelemahan } & \text { dalam } \\
\text { mengendalikan } & \text { otot } \\
\text { tenggorokan, } & \text { mulut } \\
\text { dan lidah } & \end{array}$ & & \\
\hline 16 & $\begin{array}{l}\text { Sering menderita } \\
\text { kejang }\end{array}$ & & \\
\hline 17 & $\begin{array}{l}\begin{array}{l}\text { selalu mengeluarkan } \\
\text { air liur }\end{array} \\
\end{array}$ & & \\
\hline 20 & $\begin{array}{lrr}\text { Mempunyai } & \text { paras } \\
\text { muka yang } & \text { hampir } \\
\text { sama seperti } & \text { muka } \\
\text { orang mongol } & \end{array}$ & \multirow{3}{*}{$\begin{array}{l}\text { Down } \\
\text { Syndrome }\end{array}$} & \multirow{3}{*}{$\begin{array}{l}\text { Down } \\
\text { Syndrome }\end{array}$} \\
\hline 21 & $\begin{array}{l}\text { gangguan mengunyah } \\
\text { dan menelan }\end{array}$ & & \\
\hline 22 & $\begin{array}{l}\text { mengalami } \\
\text { keterbelakangan } \\
\text { perkembangan dan } \\
\text { kelemahan kognitif }\end{array}$ & & \\
\hline
\end{tabular}

Tabel. 7: Rincian Hasil pengujian data testing non pakar dan system

\begin{tabular}{|c|c|c|c|}
\hline Kode & Gejala & Jenis Gangguan & Hasil Sistem \\
\hline 1 & $\begin{array}{ll}\text { Konsentrasi mudah } \\
\text { teralihkan }\end{array}$ & \multirow{10}{*}{ Hiperaktif } & \multirow{10}{*}{ Hiperaktif } \\
\hline 3 & Tidak sabar & & \\
\hline 4 & Suka gelisah & & \\
\hline 6 & $\begin{array}{l}\text { Pasif dalam } \\
\text { berkomunikasi }\end{array}$ & & \\
\hline 11 & $\begin{array}{ll}\text { Ekspresi } & \text { muka } \\
\text { kurang hidup }\end{array}$ & & \\
\hline 12 & $\begin{array}{l}\text { Gerak-gerik kurang } \\
\text { tertuju }\end{array}$ & & \\
\hline 13 & Terlambat bicara & & \\
\hline 18 & $\begin{array}{l}\text { Sulit mengontrol } \\
\text { gerakan menulis }\end{array}$ & & \\
\hline 19 & $\begin{array}{lr}\text { Terpaku pada } & \text { suatu } \\
\text { kegiatan } & \text { yang } \\
\text { ritualistik } & \text { atau } \\
\text { rutinitas yang tak ada } \\
\text { gunanya }\end{array}$ & & \\
\hline 22 & $\begin{array}{l}\text { mengalami } \\
\text { keterbelakangan }\end{array}$ & & \\
\hline
\end{tabular}

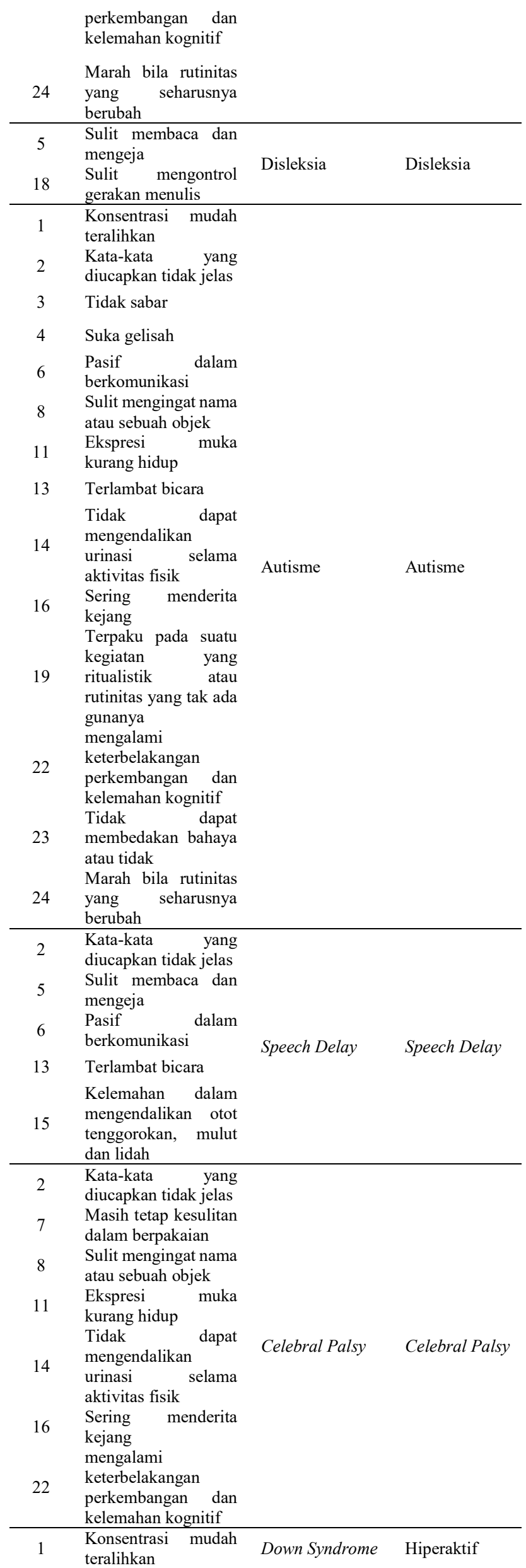


2 Kata-kata yang diucapkan tidak jelas

3 Tidak sabar

$4 \quad$ Suka gelisah

Pasif dalam

berkomunikasi

11- Ekspresi

muka

kurang hidup

2 Gerak-gerik kurang

tertuju

13 Terlambat bicara

16 Sering menderita

kejang

Terpaku pada suatu

kegiatan yang

19 ritualistik atau rutinitas yang tak ada gunanya

Mempunyai paras

muka yang hampir sama seperti muka orang Mongol

mengalami

keterbelakangan

perkembangan dan kelemahan kognitif

Marah bila rutinitas

24 yang seharusnya

berubah 